\title{
An innovative service collaboration to reduce criminal recidivism for inmates with severe addictions
}

\author{
Elan Paluck, , Michelle C.E. McCarron, * Mamata Pandey,* and Dorothy Banka ${ }^{\dagger}$
}

\begin{abstract}
Agencies with overlapping mandates can form partnerships to aid development of effective programming. In 2008, the Dedicated Substance Abuse Treatment Unit (DSATU) opened at Regina Correctional Centre through a tripartite collaboration between the Saskatchewan (SK) Ministry of Justice, Corrections and Policing; Addiction Services, Regina Qu'Appelle Health Region; and the SK Ministry of Health. Stakeholders researched existing best practices in the field and developed an evidence-based substance abuse treatment program for sentenced inmates at high risk to re-offend. An evaluation of the DSATU program completed in 2016 concluded that the DSATU was effective, sustainable, and likely transferable to other correctional facilities wishing to offer this type of programming. The stakeholder partnership was a key ingredient in the program's success. This paper describes the process by which the partners worked together to develop, implement, and sustain this innovative and evidence-based substance abuse treatment program. The partners' willingness to compromise, to take a collaborative approach to building the partnership and developing the program, and to put clients ahead of individual organizational mandates all contributed to the success of the partnership.
\end{abstract}

Key Words Correctional centre; criminogenic behaviour; criminal lifestyles training; recidivism; addiction treatment; collaboration; partnership.

Journal of CSWB. 2017 June;2(2):66-70

www.journalcswb.ca

\section{INTRODUCTION}

Inter-agency partnerships, sometimes referred to as service collaboratives, can be an effective strategy for organizations to accomplish mutual goals that would be difficult to achieve by each party in isolation, particularly when those organizations operate within different sectors. Each partner brings different resources, infrastructure, and expertise to aid the partnership. Although much of the literature addressing partnership models is based on observation, reflections on specific cases, and theory, several common characteristics of effective partnerships have nevertheless been described in the literature. Having a respected leader, pursuing a shared goal or vision, establishing clearly defined roles, and fostering open communication all serve to increase a partnership's likelihood of being effective in attaining its goals (Compassion Capital Fund, 2010; Delva, Jamieson, \& Lemieux, 2008; Roussos \& Fawcett, 2000; UNICEF, 2015).

A sizeable portion of the literature on cross-sectoral collaborations focuses on Public-Private Partnerships. With
Canadian health-care facilities being publicly funded and operating at arms' length from provincial governments, there is a unique opportunity for collaboration between different branches of the public service to provide innovative healthcare interventions. To our knowledge, however, there was no empirical evidence to date addressing the efficacy of this type of collaboration in providing a health-care service in a correctional environment.

The current study evaluated the Dedicated Substance Abuse Treatment Unit (DSATU) which is a specialized unit at the Regina Correctional Center (RCC) in Regina, Saskatchewan (SK). It provides comprehensive in-patient addiction treatment to male inmates. The project is a partnership between the SK Ministry of Justice, Corrections and Policing (CP), the Regina Qu'Appelle Health Region (RQHR), and the SK Ministry of Health.

A comprehensive evaluation of the DSATU was completed in 2016. It included a retrospective analysis of the case files of all DSATU participants (2008-09 to 2014-15 fiscal years), 39 interviews with program participants, staff, and 
stakeholders, and a retrospective, case-control analysis of DSATU program data linked with Ministry of Justice Corrections' Case Management Information System (CMIS) data (treatment group $\mathrm{n}=747$, comparator group $\mathrm{n}=535$ ). Complete results from the evaluation will be published in an upcoming edition of the Journal of CSWB. The purpose of this paper, however, is to describe the formation of the partnership that was responsible for the development and implementation of the DSATU program.

\section{Identifying the Need}

In 2005, members of the Community Justice Sub-Committee of the "Regina and Area Drug Strategy" recognized the need for intensive addictions treatment for adult inmates within provincial correctional institutions. This service was not available at the time. Inmates in correctional facilities with substance abuse problems were eligible to apply to participate in the existing addictions programming, but these programs did not offer the intensity that most of these inmates required. At that time, the majority of the inmates at RCC were assessed as high-need individuals, requiring intensive addictions treatment that was typically only available in in-patient settings in the community. However, these in-patient programs limited the number of offenders who were accepted at any one time due to their criminal thinking and history of antisocial behaviour. As a result, fewer than $3 \% 1$ of inmates in custody at RCC who required intensive addictions treatment were able to access it. The demonstrated need for this type of treatment was extensive. In 2005-06, RCC admitted just over 700 sentenced inmates. $^{2}$ Six hundred and twenty-five (625) inmates were assessed using the Offenders Risk Assessment Management System Primary Risk Assessment (ORAMSPRA). Of those assessed, 94\% $(n=587)$ had serious problems resulting from substance abuse ${ }^{2}$ and would have required moderate to high level interventions. Records show that 141 of these men participated in a low-intensity addiction treatment program, which, although relevant to their needs, would not have been a sufficient intervention for most of them.

Following the work of the Drug Strategy, a proposal was developed, provincial funds were dedicated, and a small working committee comprising senior managers from CP, RQHR Mental Health and Addiction Services, and the Ministry of Health worked together to develop the DSATU program. This group became the Governance Committee responsible for maintaining program integrity and reviewing any changes to philosophy, direction, or operation.

\section{Setting Expectations}

Within the first year of the DSATU's operation, the Governance Committee developed Terms of Reference to articulate their purpose, values, membership, decision-making process, duties, roles and responsibilities, communication, and reporting and meeting requirements. The Committee also established an Evaluation Sub-Committee Working Group. This working group included representatives from each of the partners who had the expertise to deliver and evaluate the program. The Evaluation Sub-Committee was tasked

Adult Corrections Case Management Information System (CMIS) (2005) Adult Corrections Case Management Information System (CMIS) (2005$06)$. with the responsibility of developing a detailed program description and a logic model to guide program monitoring and evaluation.

Having all parties agree on the program's goals, objectives, program delivery, and the roles and responsibilities of the partners at the onset was important in reducing misunderstandings and avoiding program drift. Creating terms of reference for the Governance Committee and having the Evaluation Sub-Committee create the program description for approval by the Governance Committees laid the foundation for a successful partnership.

\section{Implementing a Response}

The Ministry of Health, as a partner in the DSATU, reviewed the literature on best practices in substance abuse treatment, while CP provided research on effective correctional treatment. As a result, the treatment model for the DSATU Program was informed by best practices and research outlined by Health Canada (1999), Correctional Services Canada, and the Canadian Centre on Substance Abuse, and integrated with the following principles of effective correctional treatment (i.e., the Risk-Need-Responsivity model; Andrews, 2001; Andrews \& Bonta, 2006; Andrews \& Kiessling, 1980; Bonta \& Andrews, 2007; Dowden \& Andrews, 2004; Gornik, 2001; Tellier \& Serin, 2001):

1. Treatment programs need to take into account offenders' orientation, cognitive, and learning styles.

2. The most intensive intervention services need to be targeted at offenders who are assessed as being higher risk for further criminal behaviour.

3. Treatment should be designed to target criminogenic factors or needs that predict criminal behaviour. It is recognized that these factors may change during the course of treatment (e.g., substance abuse).

The curriculum was based upon the conceptual models of Cognitive Behavioural Therapy (Marlatt \& Donovan, 2005), Motivational Interviewing (Miller \& Rollnick, 1991), and Criminal Lifestyles Training (Armstrong, 1996). Other evidence-based components of the program include a criminogenic risk assessment, standardized and validated screening tools to assess treatment need and motivation, pre-post evaluation tools to assess the integrity of the programming, and aftercare and post-treatment support (Paluck, McCarron, Pandey et al., 2016a, Evaluation of the Dedicated Substance Abuse Treatment Unit program (DSATU) in the Regina Correctional Centre. Unpublished manuscript.

\section{Program Description}

The mandate of the DSATU is to reduce substance abuserelated criminogenic behaviour through the provision of an intensive dedicated treatment program for male inmates with significant substance abuse issues. It provides a fiveweek treatment program for 20 high-risk, high-need inmates. Approximately 120 inmates participate in the program on an annual basis.

Structured programming runs daily, Monday through Friday, from 8:45 a.m. to 4:00 p.m., with a 1.5 hour lunch break and a one-hour period during which all program participants are locked in their cells (in compliance with the institutional 
lock-down policy). The lunch break is also used as time to complete homework or meet one-on-one with counsellors.

The program focuses on reducing or eliminating the harmful consequences of substance abuse. Inmates' treatment goals are prioritized, emphasizing immediate and realizable goals. The curriculum is presented in a dynamic, non-didactic manner through the use of individual counselling, workshops to increase factual knowledge in the areas of substance use and in the identification of cognitive distortions that lead to anti-social behaviours, and process groups to facilitate self-reflection. Program delivery staff are given autonomy in how they deliver the material. Treatment plans are flexible, recognizing individual differences and goals, and provide a maximum range of treatment and support options. Reflecting the inmates' motivation and readiness for change, treatment goals span the continuum from reduced use to abstinence.

Staff utilize Core Correctional Practices (CCP) in the delivery of the program. CCP is a set of interaction and intervention skills that, when used by staff, increase the likelihood of positive behaviour change in offenders. These include interacting with offenders to develop positive relationships and reduce resistance in inmates, as well as intervention skills to teach pro-social ways of dealing with difficult situations (i.e., problem solving, cognitive re-structuring). RQHR addictions staff, like their counterparts from $\mathrm{CP}$, undergo training on the Barbara Armstrong Criminal Lifestyles program and anatomy of a set-up (to identify and guard against manipulative behaviours), and are given an orientation to the RCC and the program.

Cultural, spiritual, and life skills components which address antisocial values and attitudes are also integrated into the program (Armstrong, 1996). Linkages to the community through Probation Services, parole, community training resources, and RQHR Addiction Services facilitate success by providing aftercare and post-treatment options.

\section{Working Together}

\section{Roles and Responsibilities}

The contribution of the three partners differed. Representatives from the Ministry of Health conducted the initial literature review on best practices, reviewed program materials prior to approval, and provided oversight of the program at the governance level. RQHR Mental Health and Addiction Services and CP staff members were instrumental in the development of the initial proposal and program content and continue to work collaboratively to deliver programming. Representatives from all three stakeholders served as members of the DSATU Evaluation Sub-Committee, which provided leadership and expertise in the development of the program logic model and formed a plan for the future evaluation of the program.

Program staff employed by RQHR and those employed by CP fulfilled the same responsibilities with regard to their roles on the program delivery team. One CP staff member serves as the on-site program supervisor; RQHR employees report to a supervisor who is off-site, but still work closely with the program supervisor from CP. Similar to Corrections Workers (CWs); more currently known as Corrections' Officers on other units, the role of DSATU CWs is to provide security and to act as case managers for inmates.
Physical space was made available to house the participants by allocating Unit 7A in the RCC for the program. Office space was also provided for the program delivery staff. Some work was required to determine the logistics of moving participants to Unit 7A and arranging the training that the staff members delivering and managing the program would require.

The roles and responsibilities of staff, supervisors, managers, and the Governance Committee were specified in the beginning, but how they are exercised has matured over time. When the partnership was first being established and the program was being developed and implemented, communication was frequent (daily or near-daily telephone calls, e-mails, and in-person discussion) within and across organizations, and within and across "roles" (e.g., governance committee members communicating with staff developing the program). However, the role of the Governance Committee has diminished over time. This was largely attributed to the observation that the program has reached a point where it is running smoothly and there has been little perceived need for the Governance Committee to convene. This was identified by stakeholders as something that could perhaps be improved upon; even if the program continues to run smoothly, there are benefits to regular, scheduled check-ins, even if these are infrequent (McCarron, Pandey, Paluck et al., 2016b, An evaluation of the Dedicated Substance Abuse Treatment Program (DSATU) at the Regina Correctional Centre: Observations and insights from program participants, staff, and stakeholders. Unpublished manuscript.

Staff explained that, although inmates interact with program staff members quite differently than they do with CWs, the inmates do not treat program staff employed by RQHR and those employed by CP differently (McCarron et al., 2016). Part of the CWs' role is to enforce the rules on the unit and provide security along with case management duties. Given the nature of their roles, program participants build a stronger rapport with program staff and feel more comfortable opening up to them. It is important to ensure that Addiction Services staff members from the RQHR assigned to the program are a good fit for a correctional environment.

\section{Problem Solving}

There have been occasional differences of opinion arising from different organizational mandates, particularly earlier on in development. These were addressed through mutual respect, a collaborative approach to problem-solving, willingness to compromise, and by adopting a client-first mindset. Staff and stakeholders did not find any of these differences to be insurmountable (McCarron et al., 2016).

\section{Communication}

Directness of communication can be a drawback within this model. Although communication was quite cross-sectional during program development and initial implementation (i.e., across institutions and across roles), communication became more hierarchical, with information generally being communicated up and down the line from front-line staff, to managers and directors, to the Governance Committee, and vice versa.

The relationship between program delivery staff and CWs improved over time once the groups had more time to interact with, and observe, each other. In addition, management 
commented on the genuine commitment of the program staff, and it was noted that the program staff were accepted and well respected by CWs.

\section{Partnership Benefits}

Numerous benefits to this collaborative service model were identified. Offering substance abuse treatment to inmates is a positive use of their time while incarcerated, partners are able to pool resources to offer treatment services that may not otherwise be possible, and the involvement of a Regional Health Authority in the program helps facilitate continuity once inmates are released and wish to seek treatment in the community.

A particular strength of the partnership was the preexisting working relationships amongst partners. This contributed to the development of trust early on. The success of the partnership was enhanced as a result of the partners' willingness to compromise, to take a collaborative approach to building the partnership and developing the program, and to put the client ahead of individual organizational mandates, which results in improved outcomes such as reduced recidivism.

\section{Effectiveness of the Collaboration}

Results of the DSATU program evaluation completed in 2016 support the proposition that the tripartite service collaborative is effective:

DSATU participants demonstrated statistically significant improvements in pre- and post-treatment measures of knowledge, beliefs, attitudes, and skills in dealing with substance abuse issues and criminal thinking (Paluck et al., 2016a).

DSATU participants reported high levels of satisfaction with the instructors and delivery of the program, and there is a high demand for this program, with an overall completion rate of $92 \%$ (Paluck et al., 2016a).

In the period of time between completing the DSATU program and their release from the RCC, DSATU participants had a significantly lower rate of institutional misconduct (disciplinary offenses; 25\%) relative to the comparator group (46\%); (Paluck, McCarron, Pandey et al., 2016c, Impact of the Dedicated Substance Abuse Treatment Unit program on criminogenic behaviours: A 7-year retrospective analysis. Unpublished manuscript.

- Post release from the RCC, DSATU participants had a significantly lower rate of contact with correctional services (recidivism) at 6 months (17\% vs. 26\% for the comparator group) and 12 months (28\% vs. $40 \%$ for the comparator group) post-release. This difference remained significant for the 24 months following their release from RCC (Paluck et al., 2016b).

- DSATU participants who came into contact with corrections post-release took longer to do so than those in the comparator group. The median number of days until re-contact occurred in the DSATU group was 251 days compared to 158 days for the comparator group (Paluck et al., 2016b).

Stakeholders interviewed as part of the evaluation believed that this program was beneficial and would be useful to other centres interested in offering similar programming, although they may wish to adapt some content to fit their local population. Stakeholders cautioned, however, that sites wishing to build this type of partnership should invest the time upfront to build strong inter-organizational working relationships prior to implementing such a program.

The program not only improved well-being for inmates, but also saved taxpayers' dollars. Preliminary projections prepared by CP suggest that the DSATU has operated with an estimated annual net benefit of $\$ 1.1$ to $\$ 1.9$ million.

\section{CONCLUSIONS}

The partnership necessary to operationalize this program was innovative and was built upon a strong foundation of pre-existing professional relationships. The success of the partnership was bolstered by frequent multi-level, multiparty communication during program development and implementation. The stakeholders came together, researched the existing best practices in the field, and collaboratively developed an evidence-based substance abuse treatment program for inmates at high risk to re-offend. The DSATU program has been demonstrated to be highly effective at reducing recidivism. It is sustainable and likely transferable to other correctional facilities wishing to offer this type of programming.

\section{ACKNOWLEDGMENTS}

The authors wish to acknowledge the support of the Regina Qu'Appelle Health Region and the ongoing guidance from current and past members of the DSATU Evaluation Sub-Committee Working Group. A special thank you to Lorri Carlson, Executive Director, Mental Health \& Addictions Services, RQHR; Brian Danyliw, Director, Addictions Services, RQHR; Doris Schnell, Executive Director, Offender Services CP, Ministry of Justice; and long-time members of the Governance Committee for their invaluable contributions.

\section{CONFLICT OF INTEREST DISCLOSURES}

Financial support for the program evaluation was provided by the Dedicated Substance Abuse Treatment Unit (DSATU) Governance Committee, Regina, SK. It is the intent of the investigators to publish the full findings of the research as an Original Research piece in an upcoming edition of the CSWB Journal.

An abstract of the findings from this study has been submitted (under review) to the CCSAS Issues of Substance Abuse Conference (November 2017).

\section{AUTHOR AFFILIATIONS}

*Research and Performance Support, Regina Qu'Appelle Health Region, Regina, SK; ${ }^{\dagger}$ Ministry of Justice, Corrections and Policing, Government of Saskatchewan, Regina, SK, Canada.

\section{REFERENCES}

Andrews, D. A., (2001). Principles of effective correctional treatment. In L. L. Motiuk \& R.C. Serin (Eds.) Compendium 2000 on effective correctional programming (pp. 9-17). Ottawa, ON: Correctional Service of Canada.

Andrews, D. A., \& Bonta, J. (2006). The psychology of criminal conduct (4th ed.). Newark, NJ: LexisNexis.

Andrews, D. A, \& Kiessling, J. J. (1980). Program structure and effective correctional practices: A summary of the CaVIC research. In R. R. Ross \& P. Gendreau (Eds.), Effective correctional treatment (pp. 101-126). Toronto, ON: Butterworth

Armstrong, B. (1996). Lifestyles participant's manual [Manual]. Ottawa, ON: Criminal Thinking Program. 
EFFECTIVE SERVICE COLLABORATIONS IN CORRECTIONS, Paluck et al.

Bonta, J., \& Andrews, D.A. (2007). Risk-need-responsivity model for offender assessment and rehabilitation. Ottawa, ON: Public Safety Canada.

Compassion Capital Fund (2010). Partnerships: Frameworks for working together. Washington, DC: US Department of Health \& Human Services. Retrieved from http://www.strengtheningnonprofits.org/resources/ guidebooks/Partnerships.pdf

Delva, D., Jamieson, M., \& Lemieux, M. (2008). Team effectiveness in academic primary health care teams. Journal of Interprofessional Care, 22(6), 598-611. doi: 10.1080/13561820802201819

Dowden, C., \& Andrews, D. A. (2004). The importance of staff practice in delivering effective correctional treatment: A meta-analysis review of core correctional practice. International Journal of Offender Therapy and Comparative Criminology, 48(2), 203-214.

Gornik, M. (2001). Moving from correctional program to correctional strategy: Using proven practices to change criminal behavior. Boulder, CO: National Institute of Corrections. Retrieved from http://www.nicic.org/ pubs/2001/017624.pdt
Marlatt, G. A., \& Donovan, D. M. (2005). Relapse prevention: Strategies in the treatment of addictive behaviors. New York, NY: Guilford Press.

Miller, W. R., \& Rollnick, S. (1991). Motivational interviewing: Preparing people to change addictive behavior. New York, NY: Guilford Press.

Roussos, S. T., \& Fawcett, S. B. (2000). A review of collaborative partnerships as a strategy for improving community health. Annual Review of Public Health, 21, 369-402.

Tellier, C., \& Serin, R. C. (2001). The role of staff in effective program delivery. In L. L. Motiuk \& R. C. Serin (Eds.), Compendium 2000 on effective correctional programming (pp. 174-184). Ottawa, ON: Correctional Service of Canada.

UNICEF (2015). Frameworks for partnerships [website]. New York, NY: UNICEF. Retrieved from https://www.unicef.org/about/partnerships/ index_60043.htm 